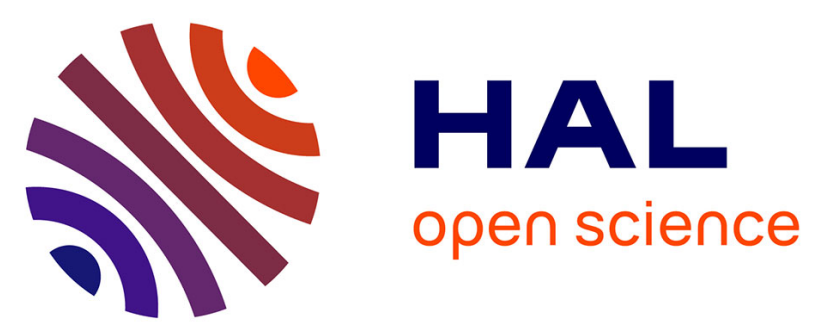

\title{
Maintenance treatment with Pegylated liposomal doxorubicin versus observation following induction chemotherapy for metastatic breast cancer: GEICAM 2001-01 study
}

Emilio Alba, Manuel Ruiz-Borrego, Mireia Margelí, Álvaro Rodríguez-Lescure, Pedro Sánchez-Rovira, Amparo Ruiz, Jose Ramón Mel-Lorenzo, Manuel Ramos-Vázquez, Nuria Ribelles, Elisa Calvo, et al.

\section{- To cite this version:}

Emilio Alba, Manuel Ruiz-Borrego, Mireia Margelí, Álvaro Rodríguez-Lescure, Pedro Sánchez-Rovira, et al.. Maintenance treatment with Pegylated liposomal doxorubicin versus observation following induction chemotherapy for metastatic breast cancer: GEICAM 2001-01 study. Breast Cancer Research and Treatment, 2010, 122 (1), pp.169-176. 10.1007/s10549-010-0860-9 . hal-00535450

\author{
HAL Id: hal-00535450 \\ https://hal.science/hal-00535450
}

Submitted on 11 Nov 2010

HAL is a multi-disciplinary open access archive for the deposit and dissemination of scientific research documents, whether they are published or not. The documents may come from teaching and research institutions in France or abroad, or from public or private research centers.
L'archive ouverte pluridisciplinaire HAL, est destinée au dépôt et à la diffusion de documents scientifiques de niveau recherche, publiés ou non, émanant des établissements d'enseignement et de recherche français ou étrangers, des laboratoires publics ou privés. 


\title{
Maintenance treatment with Pegylated liposomal doxorubicin versus observation following induction chemotherapy for metastatic breast cancer: GEICAM 2001-01 study
}

\author{
Emilio Alba • Manuel Ruiz-Borrego • Mireia Margelí • Álvaro Rodríguez-Lescure • \\ Pedro Sánchez-Rovira • Amparo Ruiz • Jose Ramón Mel-Lorenzo • Manuel Ramos-Vázquez • \\ Nuria Ribelles $\cdot$ Elisa Calvo $\cdot$ Antonio Casado $\cdot$ Antonia Márquez $\cdot$ David Vicente • \\ José Angel García-Sáenz • Miguel Martín
}

Received: 6 November 2009/ Accepted: 17 March 2010/Published online: 2 April 2010

(c) Springer Science+Business Media, LLC. 2010

\begin{abstract}
This randomized multicenter phase III trial evaluated the role of maintenance therapy with pegylated liposomal doxorubicin (PLD) after induction chemotherapy in patients with metastatic breast cancer (MBC). Patients without disease progression following first-line induction chemotherapy consisting of three cycles of doxorubicin $\left(75 \mathrm{mg} / \mathrm{m}^{2}\right)$ followed by three cycles of docetaxel $\left(100 \mathrm{mg} / \mathrm{m}^{2}\right)$ both every 21 days, were randomized to PLD $\left(40 \mathrm{mg} / \mathrm{m}^{2}\right)$ every 28 days for six cycles or to observation. Time to progression (TTP) was the primary endpoint. 288 patients
\end{abstract}

This study was conducted on behalf of the Spanish Breast Cancer Research Group (GEICAM)

Presented in part at the 43rd Annual Meeting of the American Society of Clinical Oncology, June 1-5, 2007, Chicago, IL, USA; and the European Society of Medical Oncology (ESMO), Stockholm, Sweden, September 15, 2008.

E. Alba $(\bowtie) \cdot$ N. Ribelles · A. Márquez

Department of Medical Oncology, Hospital Clínico

Universitario Virgen de la Victoria, Colonia Santa Inés s/n,

29010 Malaga, Spain

e-mail: ealbac@uma.es

M. Ruiz-Borrego · E. Calvo · D. Vicente

Department of Medical Oncology, Hospital Universitario

Virgen del Rocío, Sevilla, Spain

M. Margelí

Department of Medical Oncology, Hospital Universitario

Germans Trias I Pujol, Badalona, Barcelona, Spain

Á. Rodríguez-Lescure

Department of Medical Oncology, Hospital General

de Elche, Elche, Alicante, Spain

P. Sánchez-Rovira

Department of Medical Oncology, Complejo Hospitalario

de Jaén, Jaén, Spain were enrolled and received induction first-line chemotherapy. One hundred and fifty-five achieved response or stable disease and were randomized to maintenance PLD $(n=78)$ or observation $(n=77)$. With a median followup of 20 months from randomization (range 1-56), disease progression occurred in $94 \%$ of patients. PLD significantly improved TTP by 3.3 months ( 8.4 vs. 5.1 months; hazard ratio $[\mathrm{HR}]=0.54,95 \% \mathrm{CI}: 0.39$ to $0.76, P=0.0002$ ) compared with observation. Overall survival was not significantly prolonged with PLD (24.8 vs. 22.0 months, respectively; HR $=0.86,95 \%$ CI: $0.58-1.27, P=0.44$ ). PLD-induced toxicity was mild and manageable with up to $5 \%$ of patients experiencing grade 3/4 non-hematologic events (fatigue, mucositis, palmar-plantar erythrodysesthesia). Grade 3/4 neutropenia occurred in $12 \%$ of patients;

A. Ruiz

Department of Medical Oncology, Instituto Valenciano de Oncología, Valencia, Spain

J. R. Mel-Lorenzo

Department of Medical Oncology, Complejo Hospitalario

Xeral Calde, Lugo, Spain

M. Ramos-Vázquez

Department of Medical Oncology, Centro Oncológico de Galicia, A Coruña, Spain

A. Casado · J. A. García-Sáenz · M. Martín Department of Medical Oncology, Hospital Clínico Universitario San Carlos, Madrid, Spain 
two patients developed febrile neutropenia. This phase III trial demonstrated that maintenance chemotherapy with PLD is well tolerated and offers improved TTP in patients with MBC following first-line chemotherapy.

Keywords Breast cancer-advanced/metastatic . Pegylated liposomal doxorubicin - Maintenance therapy . Induction chemotherapy

\section{Introduction}

Metastatic breast cancer is moderately sensitive to chemotherapy. Forty to sixty percent of patients obtain a response with first-line chemotherapy, but most of them have disease progression early after treatment interruption [1]. Although the role of maintenance therapy in MBC is still undefined, its goal is to prolong the primary therapy benefit and improve disease control, while maintaining an acceptable quality of life. To date, eight out of nine randomized trials of standard versus extended duration chemotherapy in MBC patients have consistently demonstrated a progression-free survival (PFS) advantage favoring extended duration therapies [2-10]. Unfortunately, these trials have failed to demonstrate a consistent benefit in overall survival (OS), and the additional cycles of chemotherapy were often associated with a significant increase in toxicity. A meta-analysis of these trials revealed a significant $(P=0.01)$, although modest reduction in the mortality hazard with longer periods of chemotherapy [11]. This meta-analysis supports prolonged treatment in patients with $\mathrm{MBC}$ in the absence of disease progression or unacceptable toxicity. However, in a phase III trial, the administration of maintenance paclitaxel in patients achieving disease control after six to eight courses of firstline anthracycline + paclitaxel combination chemotherapy did not improve PFS, compared with patients who did not receive maintenance paclitaxel [10]. As such, the optimal duration of chemotherapy for the first-line treatment of MBC is still under debate.

Anthracyclines, including epirubicin and doxorubicin, are among the most active therapeutic agents for breast cancer. Although they are considered key components of breast cancer treatment, their toxicity profiles often preclude their long-term use. New anthracycline analogs and novel formulations have been developed to overcome these drawbacks [12, 13].

Pegylated liposomal doxorubicin (PLD; Caelyx, ScheringPlough, Kenilworth, NJ, USA) is a novel formulation of doxorubicin in a liposome matrix encased in polyethylene glycol $[12,13]$. It is designed to concentrate preferentially in tumor tissue in order to circumvent toxicity associated with the conventional anthracyclines while maintaining, or possibly improving their efficacy [12, 13]. Results from a randomized phase III trial demonstrated PLD to have similar efficacy and more importantly, a significantly reduced risk of cardiac toxicity when compared with conventional doxorubicin as first-line therapy in patients with MBC [14]. Studies have not demonstrated a significant relationship between the cumulative dose of PLD and the incidence of cardiotoxicity [14-17].

The induction chemotherapy regimen (three cycles of doxorubicin followed by three cycles of docetaxel) administered in this particular trial (2001-01) is an established GEICAM standard first-line MBC regimen. In a previous phase III trial conducted by our group (GEICAM 9903), sequential versus concomitant administration of doxorubicin and docetaxel were compared as first-line therapy for MBC [18]. Both arms demonstrated similar antitumor efficacy. However, the sequential administration was associated with less hematologic toxicity and was considered the preferred treatment arm. Hence, this sequential regimen was selected as the standard arm for future GEICAM trials. We designed a phase III trial (GEICAM 2001-01) to compare maintenance therapy with PLD versus observation following induction treatment for MBC.

\section{Patients and methods}

\section{Patient eligibility}

Patients with newly diagnosed MBC were eligible if they fulfilled the following criteria: response or stable disease (measured by the standard Response Evaluation Criteria In Solid Tumors [RECIST]) following induction chemotherapy with sequential doxorubicin and docetaxel; at least 18 years of age; an Eastern Cooperative Oncology Group (ECOG) performance status $\leq 2$; normal cardiac function confirmed by a baseline left ventricular ejection fraction (LVEF) $>50 \%$, measured by MUGA or cardiac sonography (or above the institution's lower limit of normal if different from 50\%); adequate bone marrow reserve (WBC $\geq 4 \times 10^{9} / 1$, neutrophils $\geq 2 \times 10^{9} / 1$ platelets $\geq 100 \times 10^{9} / 1$, and hemoglobin $\geq 10 \mathrm{~g} / \mathrm{dl}$ ); adequate hepatic and renal function. Written informed consent, including anticipated patient cooperation with treatment and follow-up, was obtained and documented before performing any protocolspecific procedure.

Ineligibility criteria included the following: a history of cardiac disease (class II or greater on the New York Heart Association (NYHA) scale) with congestive heart failure (CHF); hypersensitivity to anthracycline therapy or a history of severe hypersensitivity reactions to products containing Cremophor ${ }^{\circledR}$ EL; pregnancy or breast feeding; male gender; prior radiation therapy to more than one-third of 
the bone marrow or within 4 weeks before enrollment; symptomatic brain metastases; concurrent treatment for any other primary tumor except for basal or squamous cell carcinoma of the skin, or carcinoma in situ; uncontrolled bacterial, viral, or fungal infection; any condition (medical, social, or psychological) that could prevent adequate follow-up.

\section{Trial design and treatment}

This randomized, multicenter, phase III trial was conducted in 15 sites throughout Spain. The study was coordinated by the Spanish Breast Cancer Research Group (GEICAM, Grupo Español de Investigación en Cáncer de Mama). The primary endpoint of this trial was to compare time to progression (TTP) between treatment arms. Secondary endpoint was defined as the correlation of molecular markers (XPD polymorphism, tubulin_III overexpression and ERCC-1 overexpression) with response to induction therapy. Overall survival was not considered to be an endpoint in this trial. This trial was conducted in accordance with the Declaration of Helsinki, ICH Good Clinical Practice Guidelines, current Spanish guidelines, and with the approval of the appropriate ethical review boards. The study was registered at www.clinicaltrials.gov (identifier code $=$ NCT00128778).

Eligible patients received induction treatment with the standard six-cycle sequential GEICAM 9903 regimen. This regimen consisted of three cycles of doxorubicin $75 \mathrm{mg} / \mathrm{m}^{2}$ administered intravenously over 15 min every three weeks followed by three cycles of docetaxel $100 \mathrm{mg} / \mathrm{m}^{2}$ administered intravenously over $1 \mathrm{~h}$ every 3 weeks. Both agents were given on day 1 of a 21-day cycle. Patients who had received prior anthracyclines in the adjuvant setting received two cycles of doxorubicin followed by four cycles of docetaxel. Patients who achieved a response (complete or partial) or stable disease following the induction chemotherapy were randomly assigned to PLD at a dose of $40 \mathrm{mg} / \mathrm{m}^{2}$ every 28 days for six cycles, or to observation. Patients randomized to PLD received premedication with dexchlorpheniramine maleate (5 mg intravenously), ondansetron ( $8 \mathrm{mg}$ intravenously $1 \mathrm{~h}$ before chemotherapy), and dexamethasone (20 mg intravenously). If palmarplantar erythrodysesthesia (PPE; hand-foot syndrome) occurred, patients received dexamethasone $8 \mathrm{mg}$ orally on days $1-5$ and $4 \mathrm{mg}$ orally on days $6-7$.

Doses adjustments were based on the most severe toxicity observed in the previous cycle. Before day 1 of each cycle, patients had to have an adequate absolute neutrophil and platelet count. Patients with grade 4 neutropenia or thrombocytopenia received $75 \%$ of the previous dose. For PPE grade $\geq 2$, PLD was delayed for up to 2 weeks, and once recovered to grade $0-1$, resumed at $75 \%$ of previous dose. PLD was reduced by $75 \%$ in case of bilirubin
$2-3 \mathrm{mg} / \mathrm{dl}$ and to $50 \%$ in case of non-related elevation greater than $3 \mathrm{mg} / \mathrm{dl}$. For mucositis grade 1 or 2, PLD was delayed till recovery and then resumed at $75 \%$ of previous dose. Patients were not allowed to receive concurrence endocrine and/or bisphosphonate therapy.

Trial assessments and follow-up

Response to induction chemotherapy was assessed 6 weeks after the last chemotherapy dose. Following randomization, patients in both treatment arms were monitored every 28 days for 6 months. Assessment continued from 6 months to 2 years at 3 -month intervals until disease progression. Medical history, physical examination (including weight and ECOG performance status), routine laboratory tests, as well as toxicity assessment were done at each clinical visit. Tumor measurement was evaluated with the same radiological procedures used when assessing response to induction therapy. Cardiac assessments (LVEF measurements using echocardiography or MUGA) were performed at baseline (prior to maintenance therapy), at cycle 3 , cycle 6 , and every 6 months thereafter.

Toxicity was graded according to the National Cancer Institute Common Toxicity Criteria (NCI-CTC criteria, version 2).

\section{Statistical considerations}

The trial was designed to detect a hazard ratio of 0.6 for TTP with maintenance PLD. Based on our previous experience, a median TTP of 10.5 months in the observation arm was selected [18]. Assuming that TTP would conform to an exponential distribution, at least 77 patients per group were required to provide $80 \%$ power using a significance level (alpha) of 0.01 (one-sided).

The analysis of this endpoint was performed on the intention-to-treat population, defined as the randomized patients analyzed in the assigned treatment group regardless of whether or not treatment was received. Estimated median TTP was calculated using the Kaplan-Meier method and was compared between treatment arms using the log-rank test at a one-sided $1 \%$ significance level, with associated confidence intervals $(95 \% \mathrm{CI})$. The Cox proportional hazard model was used to adjust the treatment effect for potential confounding factors.

\section{Results}

Patient recruitment and characteristics

A total of 288 patients were registered over a 56-month period and received induction therapy with doxorubicin 
and docetaxel. Of these, 155 patients were randomly assigned to receive PLD maintenance therapy $(n=78)$ or observation ( $n=77$ ). Exclusions for patient enrollment into the randomized phase of the trial included disease progression or death, patient refusal, toxicity, and logistical or scheduling reasons (Fig. 1).

Patient and disease characteristics were well balanced between the two groups (Table 1). The median age of the patients was 56 years (range 30-78), with an ECOG performance status of 0 or 1 in $>90 \%$. Around $30 \%$ of the patients were stage IV at diagnosis. Approximately, threequarters of the patients had hormone-receptor-positive tumors, and half of them had dominant visceral disease. A similar number of patients in both arms had received prior adjuvant therapy (chemotherapy or hormonal treatment), with approximately one-third of them having received prior anthracyclines.

More patients in the observation arm (70\%) achieved an objective response (partial + complete) to induction therapy compared with patients randomized to receive PLD $(53 \%)$. This difference in response was almost statistically significant $(P=0.055)$. From the 37 patients with stable disease after induction therapy in the experimental arm, 6 (16\%) achieved an objective response during the maintenance phase.

Of the 78 patients randomized to receive maintenance treatment with PLD, 39 (50\%) completed all six cycles. Disease progression, occurring in $54 \%$ of patients, was the main reason for treatment discontinuation. Eight patients discontinued due to toxicity and 10 due to other reasons (mainly patient decision). A total of 339 cycles were administered, with a median number of 6 (range 0-6; Table 2). Median relative dose intensity of PLD was $97 \%$. Dose delays were documented in 46 cycles (14\%) and dose reductions in 12 cycles $(4 \%)$.

\section{Efficacy}

With a median follow-up of 20 months from randomization (range 1-56), disease progression was documented in $94 \%$ ( $n=146$ ) of patients (analysis performed August 2009). The median TTP from randomization was 8.4 months $(95 \%$ CI: 7.05-9.72) in patients receiving maintenance PLD vs. 5.1 months (95\% CI: 3.52-6.60) in the observation arm. This 3.3-month improvement was statistically significant with a hazard ratio of 0.54 (95\% CI: 0.39 to 0.76 , $P=0.0002$.

As depicted in Fig. 2, 28 patients in the PLD arm and 50 in the observation arm progressed during the first 6 months post-randomization, while 41 and 23 patients, respectively, progressed during the period of 6-24 months. Several baseline covariates (ECOG performance status, response to induction therapy, age, hormonal status, location of metastatic sites, and treatment arm) were studied using the Cox proportional hazard model (Table 3a). Two covariates were independent predictors of TTP: visceral disease

Fig. 1 GEICAM 2001-01

flowchart

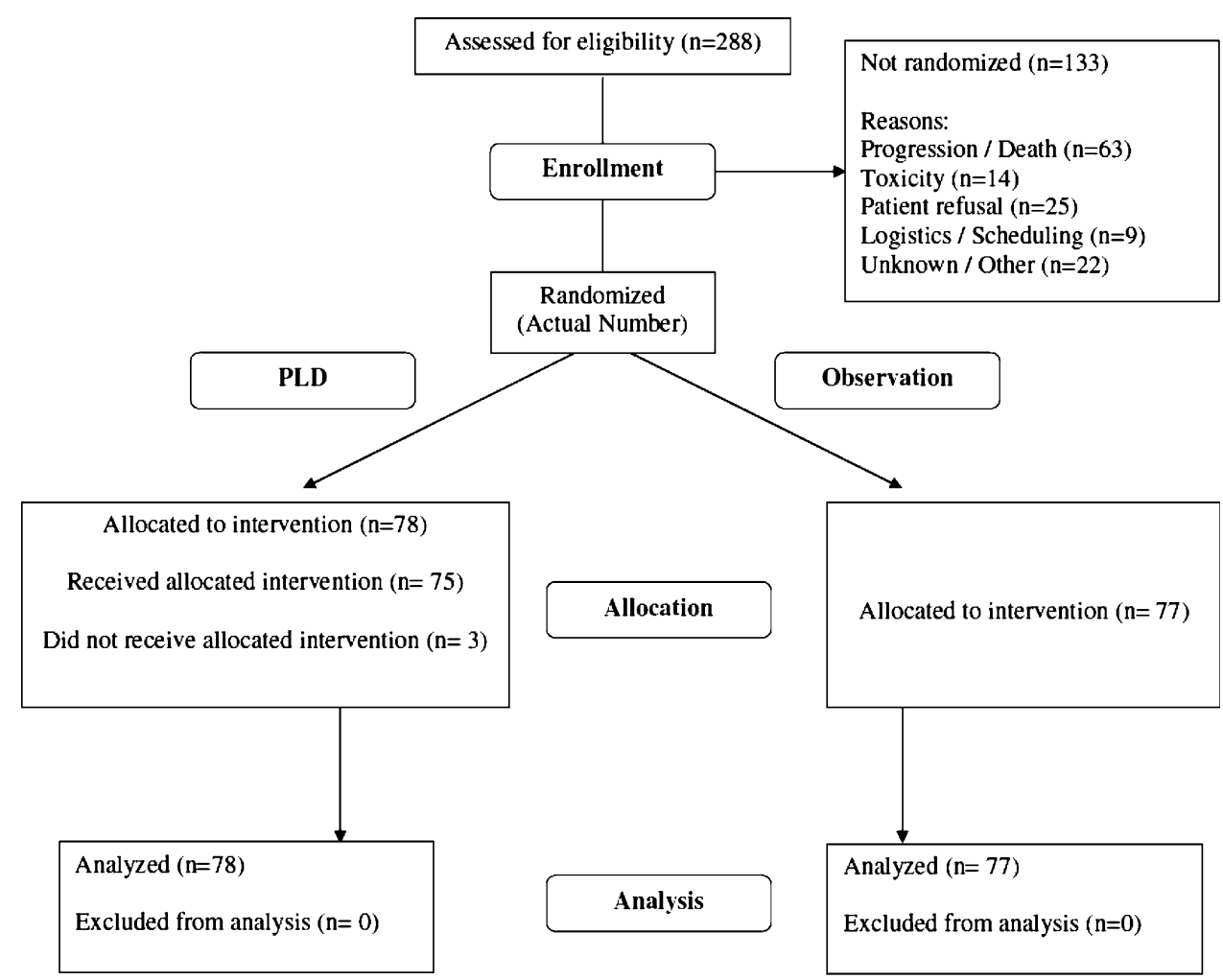


Table 1 Patient baseline, disease characteristics and prior therapy

\begin{tabular}{|c|c|c|c|c|}
\hline \multirow[t]{2}{*}{ Characteristic } & \multicolumn{2}{|c|}{$\operatorname{PLD}(n=78)$} & \multicolumn{2}{|c|}{ Observation $(n=77)$} \\
\hline & $\begin{array}{l}\text { No. of } \\
\text { patients }\end{array}$ & $\%$ & $\begin{array}{l}\text { No. of } \\
\text { patients }\end{array}$ & $\%$ \\
\hline \multicolumn{5}{|l|}{ Age, years } \\
\hline Median & 58 & & 55 & \\
\hline Range & $(30-76)$ & & $(34-78)$ & \\
\hline \multicolumn{5}{|l|}{ ECOG PS } \\
\hline 0 & 45 & 58 & 43 & 56 \\
\hline 1 & 20 & 26 & 28 & 36 \\
\hline 2 & 5 & 6 & 2 & 3 \\
\hline Unknown & 8 & 10 & 4 & 5 \\
\hline \multicolumn{5}{|l|}{ Hormonal status } \\
\hline $\mathrm{ER}+$ and/or PR+ & 53 & 68 & 56 & 73 \\
\hline $\mathrm{ER}-$ and/or PR- & 17 & 22 & 15 & 19 \\
\hline Unknown & 8 & 10 & 6 & 8 \\
\hline \multicolumn{5}{|l|}{ Dominant site of disease } \\
\hline Visceral & 46 & 59 & 43 & 56 \\
\hline Non-visceral & 31 & 40 & 31 & 40 \\
\hline Unknown & 1 & 1 & 3 & 4 \\
\hline \multicolumn{5}{|l|}{ Disease stage at diagnosis } \\
\hline I-III & 57 & 73 & 54 & 70 \\
\hline IV & 21 & 27 & 23 & 30 \\
\hline \multicolumn{5}{|l|}{ Prior (neo-) adjuvant therapy } \\
\hline Chemotherapy & 48 & 62 & 44 & 57 \\
\hline Hormonal therapy & 33 & 42 & 32 & 42 \\
\hline Prior adjuvant anthracycline & 23 & 30 & 27 & 35 \\
\hline \multicolumn{5}{|l|}{ Response status at randomization } \\
\hline Complete response & 3 & 4 & 7 & 9 \\
\hline Partial response & 38 & 49 & 47 & 61 \\
\hline Stable disease & 37 & 47 & 23 & 30 \\
\hline
\end{tabular}

$E C O G$ Eastern Cooperative Oncology Group, ER estrogen receptor, $P L D$ pegylated liposomal doxorubicin, $P R$ progesterone receptor, $P S$ performance status

Table 2 Dose administration

\begin{tabular}{lc}
\hline & PLD $(n=78)$ \\
\hline Cycles (n) & 339 \\
Mean & 4.9 \\
Median (range) & $6(0-6)$ \\
Patients completing all planned cycles & $39(50 \%)$ \\
Discontinuation reason & \\
PD or death & $21(54 \%)$ \\
Toxicity & $8(20 \%)$ \\
Other (e.g. patient choice) & $10(26 \%)$ \\
\hline
\end{tabular}

$P D$ progressive disease, $P L D$ pegylated liposomal doxorubicin

$(\mathrm{HR}=1.8 ; P=0.001)$ and treatment with PLD $(\mathrm{HR}=$ 0.53; $P=0.0002$ ) (Table 3b). Overall survival (Fig. 3) was not significantly prolonged by PLD maintenance

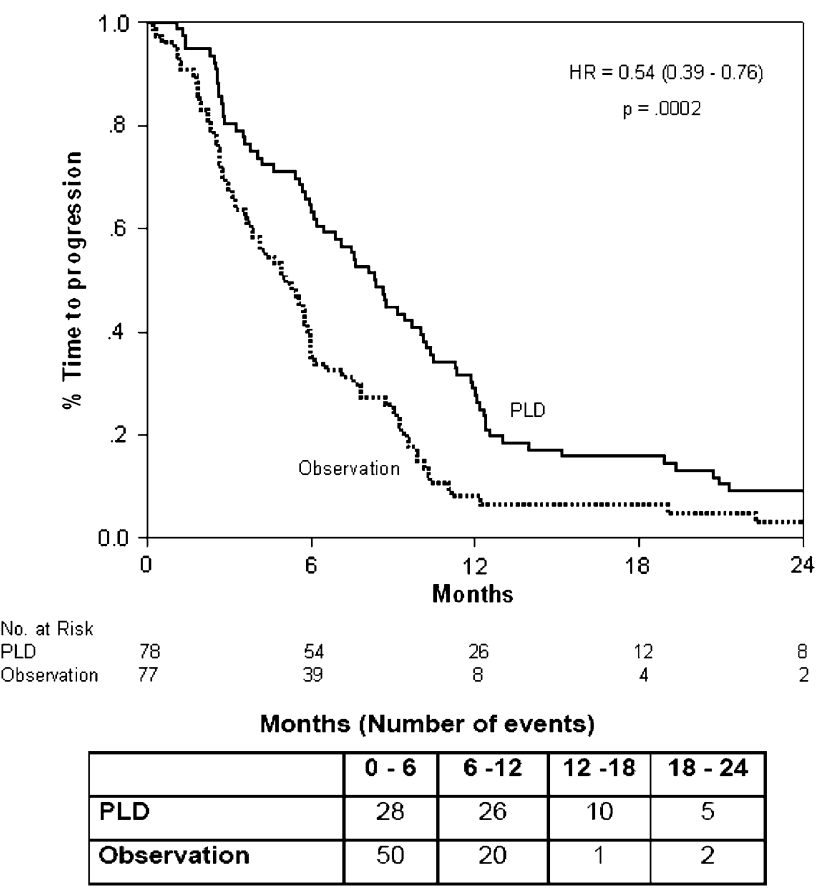

Fig. 2 Time to disease progression (TTP)

therapy, compared to the observation arm (24.8 vs. 22.0 months, respectively; $\mathrm{HR}=0.86,95 \% \mathrm{CI}: 0.58-1.27$, $P=0.435)$.

Molecular markers data are not available at the present time and will be disclosed in a separate publication.

\section{Safety}

Most of the treatment-related adverse events associated with PLD maintenance therapy were mild-to-moderate (grade 1 or 2 ) in severity (Table 4 ). Grade $1 / 2$ neutropenia and anemia occurred in 35 and $32 \%$ of patients treated with PLD and approximately $10 \%$ in the observation arm. Grade $3 / 4$ neutropenia was experienced by $12 \%$ of PLD-treated patients, with only two patients developing febrile neutropenia. Almost all cases of non-hematologic toxicity were limited to grade 1 or 2 . Grade $3 / 4$ fatigue and mucositis occurred in only 3 and $5 \%$ of PLD-treated patients. Grade 3 PPE occurred in $4 \%$ of PLD-treated patients. One severe infusion reaction was reported.

The median LVEF after three cycles and at the end of treatment was similar in both treatment arms; 61/60/ $61.50 \%$ with PLD and 63/67/60\% with observation. After three treatment cycles decreases in $\mathrm{LVEF} \geq 10 \%$ were noted in three patients, two treated with PLD and one in the observation arm. LVEF decreased below 50\% (to 48 and $43 \%$ ) in the two PLD-treated patients, both recovered to normal limits 6 months later. At the end of treatment 
Table 3 Cox proportional hazard model for TTP

\begin{tabular}{|c|c|c|c|}
\hline \multirow[t]{2}{*}{ (a) Parameters } & \multirow[t]{2}{*}{$N$} & \multicolumn{2}{|l|}{ Univariate analysis } \\
\hline & & $\operatorname{HR}(95 \% \mathrm{CI})$ & $P$ \\
\hline \multicolumn{4}{|l|}{ Hormone receptors } \\
\hline Positive & 109 & & 0.706 \\
\hline Negative & 32 & $0.95(0.63-1.42)$ & \\
\hline Unknown & 14 & $0.78(0.44-1.40)$ & \\
\hline \multicolumn{4}{|c|}{ Induction chemotherapy response } \\
\hline Stable disease & 61 & & 0.297 \\
\hline Complete response & 10 & $1.22(0.60-2.48)$ & \\
\hline Partial response & 84 & $1.31(0.93-1.84)$ & \\
\hline \multicolumn{4}{|l|}{ ECOG } \\
\hline 2 & 7 & & 0.138 \\
\hline 0 & 88 & $1.90(0.77-4.68)$ & \\
\hline 1 & 48 & $1.41(0.56-3.55)$ & \\
\hline \multicolumn{4}{|l|}{ Age } \\
\hline$<50$ years & 50 & & 0.202 \\
\hline$\geq 50$ years & 105 & $1.26(0.89-1.78)$ & \\
\hline \multicolumn{4}{|l|}{ Visceral disease } \\
\hline No visceral & 62 & & 0.002 \\
\hline Visceral & 92 & $1.72(1.22-2.41)$ & \\
\hline \multicolumn{4}{|l|}{ Treatment arm } \\
\hline Observation & 77 & & 0.003 \\
\hline PLD & 78 & $0.54(0.39-0.76)$ & \\
\hline (b) Parameters & \multicolumn{2}{|c|}{$\mathrm{HR}(95 \% \mathrm{CI})$} & $P$ \\
\hline \multicolumn{4}{|l|}{ Visceral disease } \\
\hline No visceral & & & 0.001 \\
\hline Visceral & \multicolumn{2}{|c|}{$1.76(1.25-2.46)$} & \\
\hline \multicolumn{4}{|l|}{ Treatment arm } \\
\hline Observation & & & 0.0002 \\
\hline PLD & 0.5 & $38-0.75)$ & \\
\hline
\end{tabular}

Multivariate Cox multivariate model for TTP

decreases in LVEF $\geq 10 \%$ were noted in six patients, five treated with PLD, and one in the observation arm. LVEF decreased below $50 \%$ (to 47 and $44 \%$ ) in two of the PLDtreated patients, both recovered to normal limits 6 months later. No congestive heart failure (CHF) was reported.

\section{Discussion}

Standard chemotherapy has been shown to be an effective palliative treatment for most patients with advanced breast cancer. To-date, response to treatment and TTP outcomes are suboptimal; further research is warranted. The GEICAM 2001-01 trial was designed to test whether maintenance therapy after a standard first-line chemotherapy

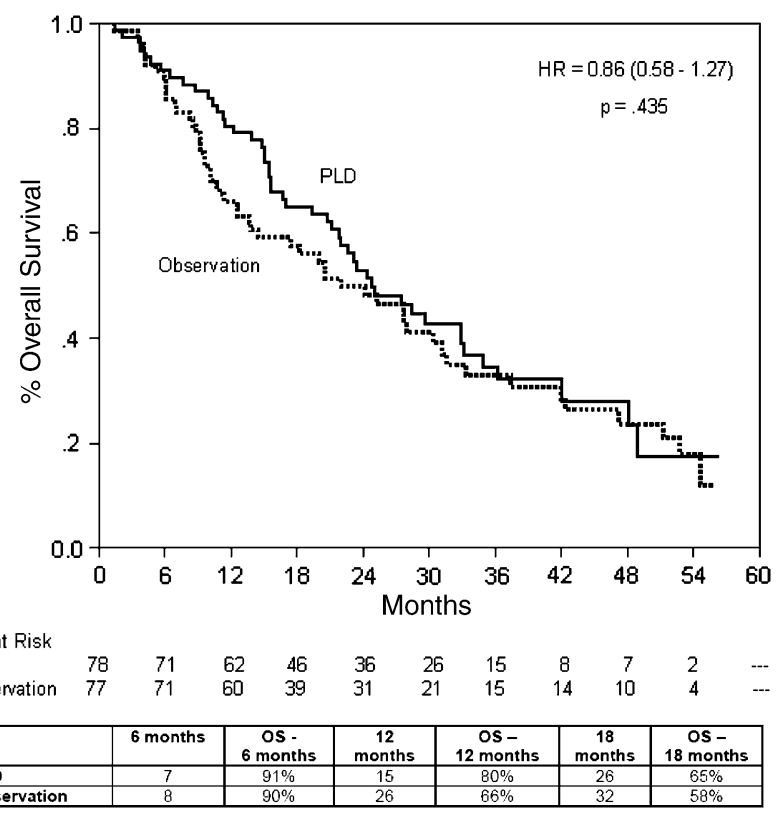

Fig. 3 Kaplan-Meier estimates of overall survival

Table 4 NCI-CTC (version 2.0) toxicity

\begin{tabular}{|c|c|c|c|c|}
\hline \multirow[t]{3}{*}{ Toxicity } & \multicolumn{4}{|c|}{$\%$ Of patients } \\
\hline & \multicolumn{2}{|c|}{$\operatorname{PLD}(n=78)$} & \multicolumn{2}{|c|}{ Observation $(n=77)$} \\
\hline & Grade $1 / 2$ & Grade $3 / 4$ & Grade $1 / 2$ & Grade $3 / 4$ \\
\hline \multicolumn{5}{|l|}{ Hematologic } \\
\hline Neutropenia & 32 & 12 & 9 & 0 \\
\hline Anemia & 35 & 0 & 12 & 0 \\
\hline \multicolumn{5}{|l|}{ Non-hematologic } \\
\hline Nausea/vomiting & 21 & 0 & 4 & 0 \\
\hline Fatigue & 32 & 3 & 8 & 0 \\
\hline Alopecia & 29 & 0 & 4 & 0 \\
\hline Infusion reaction & 1 & 1 & 0 & 0 \\
\hline Mucositis & 32 & 5 & 0 & 0 \\
\hline PPE & 29 & $4^{\mathrm{a}}$ & 0 & 0 \\
\hline
\end{tabular}

NCI-CTC.2 National Cancer Institute Common Toxicity Criteria, version 2, $P L D$ pegylated liposomal doxorubicin, $P P E$ palmar-plantar erythrodysesthesia

${ }^{\text {a }}$ Grade 3 only

regimen in patients with $\mathrm{MBC}$ would have a beneficial impact on the course of disease. TTP, an appropriate and highly sensitive endpoint for advanced disease, was utilized as a primary endpoint in this study [19]. In this phase III trial, maintenance therapy comprised of six cycles of PLD monotherapy $\left(40 \mathrm{mg} / \mathrm{m}^{2}\right.$ every 4 weeks $)$ was associated with a significantly prolonged TTP (additional 3.3 months what reflects an improvement of $65 \%$ ) in patients with MBC who demonstrated an objective response or stable disease 
following first-line chemotherapy. Median OS was not statistically different between treatment arms. Of note, this trial was not powered to determine an OS advantage with maintenance therapy.

In the present GEICAM trial, toxicities associated with PLD maintenance therapy were infrequent, mild, and manageable. The hematologic toxicity observed in both treatment arms was most likely attributable to residual toxicity from the induction chemotherapy regimen. The majority of non-hematologic toxicities reported were grade 1 or 2 and, importantly, less than $5 \%$ of the patients experienced grade 3 or 4 events. We observed a low percentage (3\% grade 3 ) of PPE using PLD $40 \mathrm{mg} / \mathrm{m}^{2}$ every 4 weeks. Of note, neither clinically relevant decrease in LVEF nor CHF events were observed in patients receiving PLD treatment.

At the time of trial initiation, questions remained regarding the optimal duration of chemotherapy for patients with metastases in the absence of disease progression. Irrespective of a lack of corroborating evidence, national and international guidelines have supported the use of chemotherapy until disease progression in the absence of unacceptable toxicity in this setting [20]. Several trials over the past two decades have demonstrated consistent prolongation of progression-free survival (PFS); however, a survival benefit or quality of life (QoL) advantage has been infrequently documented. These studies have supported the use of more protracted chemotherapy regimens [2, 4-7, 9]. Results of a meta-analysis demonstrated a modest, but statistically significant survival advantage for patients randomized to longer versus shorter treatments [11]. While these data support a continuation of chemotherapy in patients with an absence of either disease progression or unacceptable toxicity, these studies utilized older cytotoxic regimens. Since then, new cytotoxic agents and novel formulations of existing drugs have been adapted into use in clinical practice, expanding the management of MBC patients.

Though paclitaxel has demonstrated efficacy in the MBC setting, its use as maintenance therapy ( 8 weeks) following induction with an anthracycline-taxane regimen was not associated with an improvement in PFS in a phase III trial [10].The lack of benefit of maintenance paclitaxel may have been attributed to the concurrent use of hormonal therapy, paclitaxel schedule, or activity of first-line regimen utilized. GEICAM initiated the 2001-01 trial with PLD, a novel liposomal anthracycline formulation, as maintenance therapy because of its proven antitumor efficacy, safety profile, and established role in the first-line treatment of MBC [14]. Conventional anthracyclines such as doxorubicin and epirubicin are integral components in the management of women with breast cancer. However, they are of limited use because of the increasing risk of cardiotoxicity when cumulative exposure increases. In our trial, PLD was demonstrated to be a well-tolerated monotherapy that delayed disease progression. The main treatment effect with PLD was observed during treatment as evidence by the increased number of progressions after the 6-month PLD treatment period.

In conclusion, evidence from this trial shows that maintenance therapy with six cycles of PLD significantly improves TTP and is well tolerated. A sequential induction regimen of three cycles of doxorubicin followed by three cycles of docetaxel with subsequent maintenance PLD is a new therapeutic option for patients with $\mathrm{MBC}$ who have not progressed on first-line chemotherapy.

Acknowledgements The author thanks Andrés Hernando for his help in the conduction of the trial, Maribel Casas and Maria José Escudero for the statistical analyses and Dra. Eva Carrasco and Dr. Peter R. Turner for the editorial assistance. This work was research supported by Spanish Breast Cancer Research Group (GEICAM) and this study was supported in part by Schering Plough Corporation.

Conflict of interest statement None of the co-authors has any involvement that can be construed as a conflict of interest. The funding bodies were not involved in the collection and interpretation of the data, or in the decision to publish.

\section{Appendix}

See Table 5 .

Table 5 List of participating centers and investigators

\begin{tabular}{ll}
\hline Center & Principal investigators \\
\hline $\begin{array}{l}\text { Hospital Clínico Universitario Virgen de la } \\
\text { Victoria }\end{array}$ & Emilio Alba \\
Hospital Universitario Virgen del Rocío & Manuel Ruiz-Borrego \\
Hospital Clínico Universitario San Carlos & Miguel Martín \\
Hospital Universitario Germans Trias i Pujol & Mireia Margelí \\
Hospital General de Elche & Álvaro Rodríguez- \\
& Lescure \\
Complejo Hospitalario de Jaén & Pedro Sánchez-Rovira \\
Instituto Valenciano de Oncología & Amparo Ruiz \\
Complejo Hospitalario Xeral Calde & Jose Ramón Mel- \\
& Lorenzo \\
Centro Oncológico de Galicia & Manuel Ramos- \\
& Vázquez \\
Fundación Hospital de Alcorcón & Carlos Jara \\
Hospital Univeristario Marqués de Valdecilla & José Manuel López- \\
& Vega \\
Hospital Universitario Miguel Servet & Antonio Antón \\
Hospital Universitario Puerta de Hierro & Ricardo Cubedo \\
Complejo Hospitalario Juan Canalejo & Lourdes Calvo \\
Hospital Municipal de Badalona & Isabel Moreno \\
\hline
\end{tabular}




\section{References}

1. Mouridsen HT (1992) Systemic therapy of advanced breast cancer. Drugs 44(Suppl 4):17-28

2. Coates AS, Byrne M, Bishop JF et al (1987) Improving the quality of life during chemotherapy for advanced breast cancer. Intermittent versus continuous chemotherapy for breast cancer. N Engl J Med 317:1490-1495

3. Harris AL, Cantwell BM, Carmichael J et al (1990) Comparison of short-term and continuous chemotherapy (mitozantrone) for advanced breast cancer. Lancet 335:186-190

4. Muss HB, Case LD, Richards F II et al (1991) Interrupted versus continuous chemotherapy in patients with metastatic breast cancer: the Piedmont Oncology Association. N Engl J Med 325:1342-1348

5. Ejlertsen B, Pfeiffer P, Pedersen D et al (1993) Decreased efficacy of cyclophosphamide, epirubicin and 5-fluorouracil in metastatic breast cancer when reducing treatment duration from 18 to 6 months. Eur J Cancer 29A:527-531

6. Gregory RK, Powles TJ, Chang JC et al (1997) A randomized trial of six versus twelve courses of chemotherapy in metastatic carcinoma of the breast. Eur J Cancer 33:2194-2197

7. Falkson G, Gelman RS, Pandya KJ et al (1998) Eastern Cooperative Oncology Group randomized trials of observation versus maintenance therapy for patients with metastatic breast cancer in complete remission following induction treatment. J Clin Oncol 16:1669-1676

8. French Epirubicin Study Group (2000) Epirubicin-based chemotherapy in metastatic breast cancer patients: role of doseintensity and duration of treatment. J Clin Oncol 18:3115-3124

9. Nooij MA, de Haes JCJM, Beex LVAM et al (2003) Continuing chemotherapy or not after the induction treatment in advanced breast cancer patients: clinical outcomes and oncologists' preferences. Eur J Cancer 39:614-621

10. Gennari A, Amadori D, De Lena M et al (2006) Lack of benefit of maintenance paclitaxel in first-line chemotherapy in metastatic breast cancer. J Clin Oncol 24:3912-3917
11. Stockler MR, Wilcken NJC, Coates AS (2003) Chemotherapy for advanced breast cancer: how long should it continue? Breast Cancer Res Treat 81(Suppl 1):S49-S52

12. Rivera E (2003) Liposomal anthracyclines in metastatic breast cancer: clinical update. Oncologist 8(Suppl 2):3-9

13. O'Shaughnessy JA (2003) Pegylated liposomal doxorubicin in the treatment of breast cancer. Clin Breast Cancer 4(5):318-328

14. O'Brien MER, Wigler N, Inbar M et al (2004) Reduced cardiotoxicity and comparable efficacy in a phase III trial of pegylated liposomal doxorubicin $\left(\mathrm{CAELYX}^{\mathrm{TM}} /\right.$ Doxil $\left.^{\circledR}\right)$ versus conventional doxorubicin for first-line treatment of metastatic breast cancer. Ann Oncol 15:440-449

15. Safra T, Muggia F, Jeffers S et al (2000) Pegylated liposomal doxorubicin (Doxil): Reduced cardiotoxicity in patients reaching or exceeding cumulative doses of $500 \mathrm{mg} / \mathrm{m}^{2}$. Ann Oncol 11:1029-1033

16. Muggia F, Kim E, Gaiotti D, et al. (2004) Safety and response of prolonged Doxil therapy in recurrent gynecologic cancers. In: Program/proceedings of the 40th annual meeting of the American Society of Clinical Oncology, June 5-8, New Orleans, LA (abstract 5055)

17. Uyar D, Kulp B, Peterson G et al (2004) Cardiac safety profile of prolonged ( $\geq 6$ cycles) pegylated liposomal doxorubicin administration in patients with gynecologic malignancies. Gynecol Oncol 94:147-151

18. Alba E, Martín M, Ramos M et al (2004) Multicenter randomized trial comparing sequential with concomitant administration of doxorubicin and docetaxel as first-line treatment of metastatic breast cancer: A Spanish Breast Cancer Research Group (GEICAM-9903) phase III study. J Clin Oncol 22:2587-2593

19. Sargent DJ, Hayes DF (2008) Assessing the measure of a new drug: is survival the only thing that matters? J Clin Oncol 26:1922-1923

20. Beslija et al (2007) Second consensus on medical treatment of metastatic breast cancer. Ann Oncol 18(2):215-225 